\title{
RESIDÊNCIA MÉDICA: CONTRIBUIÇÖES DOS MÉDICOS RESIDENTES AO DEBATE
}

É com grande satisfação que atendemos ao chamado da Revista da Associação Médica Brasileira, que solicitou a elaboração de um texto que apresente a visão dos médicos residentes sobre a residência médica. Temos razões para acreditar que a iniciativa será um importante passo rumo ao amadurecimento de um debate que, por ora, é incipiente. Poderá, sobretudo, ter efeitos significativos para que seja estabelecida uma agenda política que reúna os diversos segmentos responsáveis pelas políticas públicas de saúde e educação em torno da residência médica, visando seu fortalecimento enquanto modalidade de especialização médica e promovendo as transformações que se fazem necessárias para qualificar a formação médica e a atenção à saúde prestada em nosso país.

Em 2007, completa 30 anos o Decreto 80.281/1977, que regulamentou a residência médica no Brasil e criou a Comissão Nacional de Residência Médica(CNRM). Antes disso, cada programa funcionava de acordo com os interesses dos serviços que ofereciam programas de residência. Passadas três décadas, ainda se observa um grande abismo entre o que ditam as normas e o que ocorre na prática. Ainda hoje há residentes submetidos a regimes de trabalho que ultrapassam 100 horas semanais (quando a lei fixa uma jornada máxima de 60 horas), plantões de mais de 36 horas ininterruptas, muitas vezes sem supervisão adequada. Mais grave ainda é isso ser encarado por muitos com naturalidade, ou pior, como algo "necessário para o aprendizado". Assim, é de se esperar que as entidades sérias, defensoras da ética profissional e compromissadas com a qualidade da formação médica e da atenção à saúde aproveitem esse momento histórico para se posicionar e tomar atitudes que estão no seu âmbito de governo para coibir essas práticas, que comprovadamente prejudicam a formação e colocam em risco a qualidade da atenção prestada à população.

O ano de 2006 foi marcado por mobilizações nacionais em torno do reajuste da bolsa de residência médica, que se encontrava bastante defasada. No Estado de São Paulo, mais de 90\% dos 6.500 médicos residentes paralisaram suas atividades por 10 dias. O reajuste foi sem dúvida a questão disparadora, mas o que deu corpo ao movimento foi a luta por melhores condições de trabalho eaprendizado. Essaluta, porsuavez, demanda políticas para especialização médica e reformas nos órgãos que regulamentam a residência médica. A pauta ampliada de reivindicações, além de fortalecer o movimento em suas bases, dando forças para o enfrentamento das rígidas hierarquias opressoras existentes nos serviços de saúde, promoveu manifestações que reuniram mais de mil pessoas, que tiveram ampla cobertura da mídia nacional e que, pela relevância das reivindicações, conquistaram o apoio da sociedade. Como conseqüência, a Lei Federal que determina o reajuste foi aprovada em tempo recorde a partir de um Projeto de Lei, sema necessidade de edição de uma Medida Provisória, como alguns alardeavam.

Conquistado o reajuste e com a garantia de que não haveria corte de bolsas (ameaça da Secretaria Estadual de Saúde de São Paulo), os residentes do Estado de São Paulo não mantiveram a paralisação um dia além do necessário. Essa posição foi tomada por se ter clareza de que melhorias nas condições de trabalho e aprendizado não seriam resolvidas com "canetadas", até porque grande parte do que se reivindica já está previsto em lei. Essas reivindicações só poderão ser atendidas com mudanças estruturais no funcionamento dos serviços que oferecem programas de residência, nos quais, muitas vezes, o residente se insere no processo de trabalho não como um aprendiz, mas como "tocador de serviço" ou "mão-de-obra barata".

Mudar essa lógica, que se encontra profundamente enraizada nas instituiç̧ões de saúde, universitárias ou não, demanda construção de políticas que interfiram sobre essa estrutura, mas, sobretudo, exige um trabalho com a nossa própria categoria, visando a sua conscientização, pois em sua grande maioria são médicos os responsáveis pela determinação da organização dos processos de trabalho nos serviços de saúde que promovem a exploração do trabalho do médico residente.

Ao participar da Comissão Estadual de Residência Médica do Estado de São Paulo (Cerem-SP), pudemos ter contato com a pluralidade de programas e de instituições que nos mostram que a residência médica não é um todo homogêneo; pelo contrário, os programas de residência se organizam levando em conta as particularidades de suas especialidades, mas, sobretudo, as características dos serviços de saúde.

Temos nos deparado com situações absurdas, das quais podemos citar dois exemplos gritantes: residentes de Clínica Médica responsabilizados a passar visita em enfermaria de Pediatria, sem o menor sentido pedagógico para tanto, apenas para atender a uma demanda do hospital; residentes que havia mais de seis meses não realizavam determinados procedimentos fundamentais à formação em sua especialidade, em razão de aparelhos estarem quebrados, enquanto seus chefes nada faziam, pois se beneficiavam do aumento na demanda em suas clínicas particulares.

Seria possível enumerar diversos exemplos de absurdos que acontecem e que não são denunciados por medo de represálias imediatas ou de ameaças quanto a perseguição profissional futura. Para casos extremos como esses, quando chegam à Cerem-SP, não há outra medida a não ser o descredenciamento do programa e o remanejamento dos residentes para outras instituições. Porém, esses casos representam a minoria de um universo de em torno de 800 programas de residência médica existentes no Estado de São Paulo.

Na maioria dos programas, existem profissionais comprometidos com a formação médica e a prestação de uma atenção à saúde de qualidade, que acreditam na residência médica como fator de qualificação dos serviços. Assim, na grande maioria das vezes, o que observamos são problemas organizacionais, passíveis de serem corrigidos com adequada orientação - além dos excessos de carga horária e problemas de supervisão, que já são vistos com assustadora naturalidade. Para esse tipo de problema, no entanto, as Cerems são totalmente inoperantes. Não por falta de interesse ou de capacidade dos membros que a integram, mas por absolutafalta de estrutura para 
responder às demandas. A título de exemplo, somente em 2006 a Cerem-SP teve de realizar 300 vistorias. Esse trabalho hercúleo, ainda por cima, é realizado sem qualquer tipo de apoio financeiro; na maioria das vezes, os vistoriadores tiveram que arcar até mesmo com o custo de seu deslocamento!

Além do fortalecimento das Cerems, é preciso que ocorram mudanças na composição e funcionamento das Comissões de Residência Médica (Coremes), das próprias Cerems e da Comissão Nacional de Residência Médica (CNRM). Além de não representar todos os segmentos que participam do financiamento e do funcionamento da residência médica, a CNRM não consegue estabelecer uma relação harmônica com as Cerems. Por isso, a maioria de suas normas quanto à organização dos programas não é executada na prática, justificando o abismo existente entre a legislação e a realidade. Os programas de residência médica seguem lógicas próprias que variam de acordo com o funcionamento dos serviços. Jáa maioria das Coremes funcionam como "rainhas da Inglaterra": realizam apenas tarefas administrativas, sem ter a mínima interferência sobre o funcionamento dos programas.

Quando reivindicamos melhores condições de trabalho e aprendizado na residência médica e fortalecimento dos órgãos que a regulamentam, não podemos deixar de colocar esse debate no contexto de como se configura a especialização médica no Brasil. A residência médica é uma dasformas de especialização. Éreconhecida mundialmente como a melhor forma, pois promove a formação em serviços de saúde, aliando saber e prática. Por se caracterizar como momento da formação, deve ter um programa pedagógico e supervisão em serviço. Por produzirtrabalho, deve ser remunerada, de acordo com a dimensão social do trabalho produzido e a responsabilidade assumida pelo residente. No entanto, aresidênciamédicanãoéaúnica maneira de formação de especialistas. Existem também estágios e especializações que funcionam em paralelo à residência, ou seja, por meio do aprendizado em serviço, no qual o especializando também produz trabalho, mas não recebe por isso, caracterizando a exploração do trabalho médico. Ajustificativa utilizada para tal exploração é queo especializando paga sua formação com o próprio trabalho. Alguns serviços, não satisfeitos, chegam ao cúmulo de cobrar (caro) por isso. Essa práticaéendossada por Sociedades de Especialidade Médica, que conferem aos estágios papel equivalente ao da residência médica enquanto requisito para seus sistemas de titulação. Vale lembrar que, de acordo coma Lei Federal 6.932/198I, a residência médica confere Título de Especialista com validade legal, independentemente das provas de título das Sociedades. O mesmo não vale para os estágios, que geralmente funcionamà margem da lei.

Esse duplo mecanismo de formação de especialistas influencia sobremaneira as políticas para residência médica, visto que funcionam como "válvulas de escape" para a não ampliação do número de vagas para residência médica. Enquanto o número de bolsas para residência médica encontra-se estagnado, ocorre uma proliferação desenfreada e sem controle dos estágios, acompanhando um mercado que se abre com o aumento do número de egressos dos cursos de medicina.

Nesse ponto cabe uma reflexão sobre o financiamento da residência médica. É comum ouvir de representantes do governo, mas às vezes também das entidades médicas, que a residência seria uma modalidade de formação muito cara, insustentável em um país cujos orçamentos públicos estão cada vez mais estrangulados por outras prioridades.

Tal argumento não se sustenta quando confrontado com alguns números. Atualmente, os médicos residentes recebem uma bolsa de $\mathrm{R} \$$ 1.916,45 por mês, sem encargos trabalhistas, sem décimoterceiro salário. Considerando a jornada de 60 horas semanais (prevista em lei, mas muitas vezes excedida), o custo aproximado da hora de trabalho de um residente é de apenas $R \$ 7,98$. Ou seja, do ponto de vista meramente contábil, aforça de trabalho dos residentes é muito barata! Considerando quea residência médica deveservista como uma política estratégica para o sistema de saúde, fica ainda mais clara a pequena dimensão de seu "custo" dentro dos orçamentos públicos. As bolsas dos cerca de 17.000 médicos residentes custarão, em 2007, cerca de $\mathrm{R} \$ 400$ milhões, divididos entre diversas fontes pagadoras. É muito dinheiro em termos absolutos, mas não chega a $0,9 \%$ dos $R \$$ 45 bilhões destinados à Saúde no Orçamento da União...

Lutar por melhorias nas condições de trabalho e aprendizado dos médicos residentes requer melhorias na legislação da residência médica e, sobretudo, seu cumprimento. Para tanto, é necessário fortalecer seus órgãos de regulamentação. O que significa reafirmar o controle público sobre a formação médica. Controle esse que deve ser realizado com participação efetiva da sociedade civil, representada por meio de seus órgãos de classe, com o qual as Sociedades de Especialidade têm papel fundamental na definição de critérios de qualidade técnico-científica. Por outro lado, a privatização absoluta desse controle, delegando-o exclusivamente a essas mesmas Sociedades, a exemplo do quetem sido proposto para as áreas de atuação ("subespecialidades"), incorrerá no começo do fim da residência. Ao invés de avançar, retrocederemos 30 anos, voltando a algo semeIhante ao que existia antes de sua regulamentação.

Agradecemos, mais uma vez, o Conselho Editorial desta Revista pela oportunidade de dialogar com nossa categoria e pedir às nossas entidades representativas maior empenho na luta pelo fim das diferentes formas de exploração do trabalho médico, a começar pela extinção de qualquer tipo de trabalho médico que seja realizado sem a devida remuneração, mesmo em fase de treinamento. Essa não é apenas uma luta corporativa pela dignidade do trabalho médico; tem impacto significativo na qualidade da formação e da atenção à saúde prestada à nossa população. Pedimos também mais empenho na construção de uma agenda que envolva representantes das Sociedades de Especialidade, dos gestores do Sistema Único de Saúde e das instituições formadoras visando a formulação de políticas para especialização que aproximem a formação médica das necessidades de saúde contemporâneas do nosso país. 